\title{
FREUD E AS NEUROSES ATUAIS: AS PRIMEIRAS OBSERVAÇÕES PSICANALÍTICAS DOS QUADROS BORDERLINE?
}

\author{
Camila Junqueira* \\ Nelson Ernesto Coelho Junior**
}

\section{RESUMO}

Ao admitirmos que os quadros borderline e as denominadas patologias da contemporaneidade freqüentemente associadas a esses quadros não são propriamente novos, resta saber como apareciam no passado. Um retorno a Freud sugere que as "neuroses atuais" correspondem às primeiras observaçōes psicanalíticas dessas manifestaçōes; ainda que a hipótese etiológica formulada por Freud sobre as "neuroses atuais", baseada no acúmulo de tensão sexual, precise ser revista. Atualmente seria difícil sustentar a idéia de que uma patologia psíquica encontra suas origens exclusivamente na falta de satisfações sexuais, em sua acepção genital. Contudo, se tomarmos "sexual" como sendo o propriamente pulsional, tal qual Freud parecia privilegiar, é bastante coerente afirmar que essas patologias resultam da transformação direta - não mediada pelo psiquismo - da pulsão não satisfeita. Neste retorno a Freud é também possível encontrar algumas pistas para a construção de uma nova hipótese etiológica, baseada nas neuroses narcísicas.

Palavras-chave: neuroses atuais, borderline, patologias contemporâneas, psicanálise

\section{AbSTRACT}

FREUD AND THE ACTUAL NEUROSIS: THE FIRST PSYCHOANALYTICAL OBSERVATION OF BORDERLINE CASES?

If we admit that the borderline cases and the so called contemporary pathologies, frequently associated with these cases, are not properly new, we still must ask how they appeared in past times. Looking back into Freud's theory we may find that the "actual neurosis" was the first

* Psicanalista; Mestre; Doutoranda do Instituto de Psicologia da USP.

** Psicanalista; Doutor em Psicologia Clínica (PUC-SP); Professor; Pesquisador e Orientador do Instituto de Psicologia da Universidade de São Paulo - USP. 
psychoanalytical observation of this type of manifestation; even though, the etiologic hypothesis proposed by Frend must be reviewed. Nowadays it would be difficult to support the idea that a psychic pathology finds its origins exclusively in the lack of sexual satisfaction, in the genital sense. However, if we take "sexual" in the instinct (trieb) sense, as Freud appeared to privilege, it is very coherent to affirm that these pathologies result of the direct transformation - nonmediated by the psychic - of the instinct (trieb) non-satisfied. In these return to Freud it is also possible to find some clues to the construction of a new etiologic hypothesis based on the narcissistic neurosis.

Keywords: actual neurosis, borderline, contemporary pathologies, psychoanalysis

Certas manifestações, tais como, doenças psicossomáticas graves, adições, e parte dos transtornos alimentares, atualmente agrupados por diversos autores como parte do heterogêneo grupo dos quadros borderline, têm representado um grande desafio para a técnica analítica, na medida em que colocam em xeque suas principais premissas: a associação livre, a transferência, a interpretação e a manutenção do setting; diante disso, as pesquisas psicanalíticas têm buscado avançar sobre esse ponto, trazendo novas propostas de intervenção (Chabert, 1999; Figueiredo, 2003; Mayer, 2004). Entretanto, ao lado dessa discussão acerca dos modos de intervenção, os psicanalistas têm se perguntado se esses quadros configuram novas patologias, ou se há, na realidade, um aumento na freqüência (e em nossa forma de conceber) de patologias que, de fato, sempre existiram. Sobre o aumento da freqüência desses quadros na atualidade, a literatura psicanalítica tem sugerido como principal causa a perda das tradiçôes e da história em conseqüência da globalização e do tipo de relação subjetiva presente na sociedade de consumo ditada pelo capitalismo (Safra, 2000; Hegenberg, 2000; Uchitel, 2002; Viluttis, 2002, entre outros). Contudo, se admitimos que essas manifestações não são propriamente novas, nos resta a questão: como elas se apresentavam no passado? Acreditamos que um retorno a Freud nos sugere que as "neuroses atuais" foram as primeiras observaçôes psicanalíticas dessas manifestações (ou dos, denominados atualmente, quadros borderline, ou patologias contemporâneas); ainda que a hipótese etiológica formulada por Freud sobre as "neuroses atuais" baseada numa lesão tóxica ou no acúmulo de tensão sexual precise ser revista para que uma teoria etiológica mais complexa possa ser construída. Nesse retorno a Freud é possível também encontrar algumas pistas para a construção dessa nova hipótese etiológica, como será visto a seguir.

Para Freud (1905, 1923, 1925), a principal diferença entre as neuroses atuais e as psiconeuroses podia ser estabelecida por meio da etiologia: enquanto as primeiras eram tidas como conseqüência, por interferência química, de impedi- 
mentos da satisfação sexual na vida atual, as psiconeuroses eram vistas como conseqüência, por intermediação psíquica, de fixações e desvios da libido na infância. Segundo, Strachey, editor da Standard Edition,

A verdade é que, em 1895, Freud encontrava-se a meio caminho no processo de passar das explicações fisiológicas dos estados psicopatológicos para as explicaçóes psicológicas. Por um lado, propunha o que era, em linhas gerais, uma explicação química das neuroses "atuais" - neurastenia e neurose de angústia (em seus dois artigos sobre neurose de angústia, [Quais são os fundamentos para destacar uma síndrome específica denominada neurose de angústia e Respostas às críticas a meu artigo sobre a neurose de angustia] 1895), e, por outro, propunha uma explicação essencialmente psicológica - em termos de "defesa" e "recalcamento" - para a histeria e as obsessões (em seus dois artigos sobre As neuropsicoses de defesa, 1894 e 1896). Sua formação anterior e sua carreira como neurologista levavam-no a resistir à aceitação das explicações psicológicas como definitivas; e ele estava empenhado em elaborar uma estrutura complexa de hipóteses destinadas a possibilitar a descrição dos eventos mentais em termos puramente neurológicos. Essa tentativa culminou no "Projeto" e foi abandonada não muito depois. Até o fim da vida, porém, Freud continuou adepto da etiologia química das neuroses "atuais" e a acreditar que se acabaria encontrando uma base física para todos os fenômenos mentais. Entrementes, ele chegou pouco a pouco ao ponto de vista expresso por Breuer de que os processos psíquicos só podem ser tratados na linguagem da psicologia (Strachey, 1969: 27).

Todavia, Freud deixou o tratamento das neuroses atuais de lado. Segundo ele, tanto os sintomas das psiconeuroses como das neuroses atuais são o resultado de um uso anormal da libido:

[...] os sintomas das neuroses "atuais" - pressão intracraniana, sensações de dor, estado de irritação em um órgão, enfraquecimento ou inibição de uma função - não têm nenhum "sentido", nenhum significado psíquico. Não só se manifestam predominantemente no corpo (como, por exemplo, os sintomas histéricos entre outros), como também constituem eles próprios processos inteiramente somáticos, em cuja origem estão ausentes todos os complicados mecanismos mentais que já conhecemos [...] se, nos sintomas das psiconeuroses, nos familiarizamos com as manifestações de distúrbios na atuação psíquica da função sexual, não nos surpreenderemos ao encontrar nas neuroses "atuais" as conseqüências somáticas diretas desses distúrbios sexuais (Freud, 1917/1969: 452). 
Essa idéia já estava presente quando Freud afirma, nas "Contribuiçôes a um debate sobre a masturbação", que
a prisão-de-ventre, as dores de cabeça e a fadiga do chamado neurastênico não admitem serem remontadas, histórica ou simbolicamente, a experiências operantes e não podem ser compreendidas como substitutos da satisfação sexu- al ou como conciliações entre impulsos pulsionais opostos, como é o caso dos sintomas psiconeuróticos (ainda que os últimos talvez possam ter a mesma apa- rência) (Freud, 1912/1969: 314).

Porém, nesse texto, Freud se mostra mais otimista quanto ao alcance da psicanálise diante desses quadros, ao afirmar que não pode esperar a cura analítica, mas pelo menos uma melhora dos danos através do aumento da tolerância do paciente aos sintomas ou de uma mudança no regime sexual (Freud, 1912/1969). Ao que parece, esta idéia perde força nos textos subseqüientes.

Para Freud, as neuroses atuais tinham características semelhantes aos quadros de intoxicação orgânica, o que acabou deixando muito pouco espaço para a atuação da terapia psicanalítica e também para desenvolvimento de hipóteses metapsicológicas. Justificando porque não deu inicio à sua conferência sobre "O estado neurótico comum” (Freud, 1917/1969: 453-4) pela descrição destes quadros, ele escreve:

os problemas das neuroses atuais, cujos sintomas provavelmente são gerados por lesão tóxica direta, não oferecem à psicanálise qualquer outro ponto de ataque. Ela pouco pode fazer para esclarecê-los e deve deixar essa tarefa para a pesquisa bioquímica [...] por essa razão, as neuroses "atuais", improdutivas no que concerne à psicanálise, não podiam mais ocupar um lugar em primeiro plano (Freud, 1917/1969: 453).

Mas, ainda sim, Freud mantém algum interesse nas neuroses atuais e distingue três formas puras: neurastenia, neurose de angústia e hipocondria.

O termo "neuroses atuais" foi aos poucos ficando escasso na obra de Freud e sua última aparição foi em 1925, nos "estudos autobiográficos", quando ele reafirma a convicção em seus achados:

Desde aquela época não tive oportunidade de voltar à pesquisa das "neuroses atuais" nem essa parte do meu trabalho foi continuada por outro. Se hoje lanço um olhar retrospectivo aos meus primeiros achados, eles me surpreendem como sendo os primeiros delineamentos toscos daquilo que é provavelmente um assunto 
muito mais complicado. Mas no todo ainda me parecem válidos. Teria ficado muito satisfeito se tivesse sido capaz, posteriormente, de proceder a um exame psicanalítico de mais alguns casos de neurastenia juvenil, mas infelizmente não surgiu a ocasião. A fim de evitar concepçôes errôneas, gostaria de esclarecer que estou longe de negar a existência de conflitos mentais e de complexos neuróticos na neurastenia. Tudo que estou afirmando é que os sintomas desses pacientes não são mentalmente determinados ou removiveis pela análise, mas devem ser considerados como conseqüências tóxicas diretas de processos químicos sexuais perturbados (Freud, 1925/1969: 38-9; grifo nosso).

Também é possível observar nas "Novas conferencias introdutórias" (1932/ 1969) que Freud realmente nunca abandonou por completo suas idéias sobre as neuroses atuais quando fala sobre a neurose de angústia, uma das três formas de neurose atual, ao escrever sobre as três formas da ansiedade neurótica:

Em primeiro lugar, encontramo-la [a ansiedade] na forma livremente flutuante, um estado de apreensão difusa, pronta a vincular-se temporariamente, sob a forma do que se conhece como "ansiedade expectante", a qualquer possibilidade que de imediato possa surgir - como acontece, por exemplo, numa neurose de angústia típica. Em segundo lugar, encontramo-la firmemente vinculada a determinadas idéias, nas chamadas "fobias", em que ainda é possível reconhecer uma relação com um perigo externo, nas quais, porém, devemos considerar que o medo é exagerado, desproporcionado. Em terceiro e último lugar, encontramos a ansiedade na histeria e em outras formas de neurose grave, onde ou ela acompanha os sintomas, ou surge independentemente como ataque, ou como estado mais persistente, mas sempre sem qualquer base visível em um perigo externo [...] A causa mais comum da neurose de angústia é a excitação não consumada. A excitação libidinal é despertada mas não satisfeita, não utilizada; o estado de apreensão surge, então, no lugar dessa libido que foi desviada de sua utilização [...] As fobias infantis e a expectativa ansiosa da neurose de angústia nos oferecem dois exemplos da maneira como se origina a ansiedade neurótica: transformação direta da libido [...] Não faz, pois, nenhuma diferença essencial [para o que está sendo discutido] por que razão uma quota de libido se tornou não-utilizável: se é por causa da debilidade infantil do ego, como nas fobias de crianças, ou se épor causa de processos somáticos da vida sexual, como na neurose de angústia, ou se devido à repressão, como na histeria (Freud, 1932/1969: 85-6; grifos nosso).

Nesse trecho, Freud mantém a classificação de neurose de angústia, uma das neuroses atuais, relacionada aos processos somáticos e à expressão da libido sem mediação psíquica. 
Ferraz (1996: 37) pondera que no desenvolvimento ulterior da psicanálise as neuroses atuais perderam força como classificação nosológica, embora tenham mantido grande importância teórica. Laplanche e Pontalis (1967: 299-301) apontam que elas nos levam diretamente às concepçôes modernas de psicossomática e dizem que talvez a insistência de Freud na não-satisfação sexual como fator etiológico tenha atrapalhado o desenvolvimento do conceito. Mas é fundamental a antevisão de Freud de que o sintoma psicossomático não se constituía como retorno do recalcado e sim como uma transformação direta (não-mediada pelo simbólico) da libido não satisfeita.

Nossa idéia é que esses quadros descritos por Freud não dizem respeito apenas às doenças psicossomáticas, mas também às demais doenças que hoje constituem o bastante heterogêneo grupo das patologias borderline ou quadros-limite e que são caracterizados pela ausência de significado simbólico nos sintomas. Para Horn e Almeida (2003: 72-3), as neuroses atuais nos fazem pensar que o psíquico não esgota as possibilidades da experiência humana, elas nos fazem entrar em contato com um campo de vazios psíquicos, onde as condições para a formação de objetos, representantes psíquicos das pulsões, não se cumprem.

Para Zusman (1994), a diferença que Freud traça entre as neuroses atuais e as psiconeuroses vai muito além de uma delimitação nosológica, "ela marcava a existência de um fosso que separa os processo simbólicos de uma outra forma de 'pensar' para a qual não há um nome definido no campo da psicanálise” e para o qual esse autor vai propor o nome "sígnico" (Zusman, 1994: 154). Os processos simbólicos e a histeria foram a matriz da psicanálise, mas isso não dá conta de todos os fenômenos da clínica, há problemas que aparecem no corpo que não podem ser reduzidos a conversões histéricas. Existe um grupo de pacientes que apresenta somatizações, que tem uma vida de fantasia muito empobrecida e baixa tolerância a interpretaçōes, que Zusman identifica com a descrição freudiana das neuroses atuais, quadro clínico que ficou relegado à orfandade quando o foco se dirigiu para os processos simbólicos e para as psiconeuroses.

Zusman (1994) nos lembra que a transferência, chave do tratamento analítico, também se assenta sobre processos simbólicos, que não estão plenamente ao alcance de todos. $\mathrm{O}$ símbolo se define pela propriedade de representar o objeto na ausência do mesmo, é um instrumento do pensamento e é marca distintiva da condição humana, porém o aparecimento dos recursos de simbolização não implica o desaparecimento dos recursos sígnicos pré-existentes.

A linha divisória que Freud traçou separando as psiconeuroses das neuroses atuais corresponde, assim, ao divisor de águas que agrupa em um de seus lados 
as vicissitudes do processo simbólico e, no outro, o do processo sígnico [...] na prática clínica, nos consultórios psicanalíticos as neuroses atuais ganham um tratamento idêntico ao das psiconeuroses, ainda que a resposta terapêutica a estas interpretaçôes seja freqüentemente precária [...] O pensamento sígnico é um pensamento do corpo, no corpo, que não ganhou transformação simbólica, e que se anuncia como ação motora, secretória ou visceral [...] o usual é que a interpretação simbólica não alcance a camada sígnica (Zusman, 1994: 158-60).

Deste modo, acreditamos, por um lado, que a hipótese etiológica freudiana sobre a formação das neuroses atuais, que se baseava na não-satisfação sexual direta, precisa ser abandonada para que uma teoria mais complexa possa ser pensada. Por outro lado, ao que parece, as observações de Freud sobre os quadros denominados de neuroses atuais, que se caracterizam pela formação de sintomas não mediados pelo simbólico, foram as primeiras observações psicanalíticas do que hoje segue a denominação de patologias atuais, casos-limite ou borderline e que inclui os distúrbios psicossomáticos, assim como algumas formas de distúrbios alimentares e adições.

Atualmente, seria difícil sustentar a idéia de Freud de que uma patologia psíquica encontra suas origens exclusivamente na falta de satisfações sexuais, em sua acepção genital. Contudo, se tomarmos "sexual" como sendo o propriamente pulsional, tal qual Freud mesmo parecia privilegiar, é bastante coerente afirmar que essas patologias resultam da transformação direta - não mediada pelo psiquismo - da pulsão não-satisfeita. Com isso, a questão passa a ser por que essa mediação não ocorreu. Hipóteses sobre as falhas na relação mãe-bebê ajudam a compreender que a mediação psíquica pode falhar não apenas em situações traumáticas, onde há um excesso pulsional, mas também em razão de prejuízos na constituição do aparelho psíquico, entendido aqui como um aparelho mediador. Também podemos pensar que algumas doenças somáticas são mais mediatizadas que outras, ou seja, fazem parte de quadros neuróticos, enquanto outras, descritivamente semelhantes, são menos ou quase nada mediatizadas, fazendo parte dos quadros limites (onde há falhas na constituição dos limites do psiquismo). Vale também lembrar que parte da literatura atual na área tem apontado que a anorexia pode ser encontrada dentro de quadros de histeria ou se apresentar como pura descarga, podendo ser colocada no rol dos quadros limite (Scazufca e Berlink, 2004).

Nas "Conferências introdutórias" (1917/1969), Freud expôs algumas idéias sobre as neuroses narcísicas que nos servem para pensar uma outra etiologia para as neuroses atuais (e com isso, também, uma outra etiologia para as patologias 
borderline). A partir da consideração de que o narcisismo é um estádio universal e original no qual as pulsões estão completamente voltadas para o ego, Freud estabelece que durante o desenvolvimento normal da libido esta deve progressivamente ser dirigida aos objetos, sem que o narcisismo, no entanto, desapareça totalmente. Porém, se a libido não encontra mais satisfação nesses objetos, por sua ausência na realidade ou por efeito da repressão, a tendência da libido é regredir para objetos e meios de satisfação mais primitivos - pontos de fixação que se constituíram na história do desenvolvimento da libido daquele indivíduo. Segundo Freud (1917/1969: 491), o processo que desliga a libido dos objetos e bloqueia seu retorno a eles é estreitamente relacionado ao processo de repressão. Contudo, se nas neuroses narcísicas o resultado é diferente do que ocorre na histeria (ou psiconeuroses em geral), isto se deve a fatores constitucionais, ou seja, o ponto de fixação da libido deve ter ocorrido em fases muito mais precoces do desenvolvimento, provavelmente na fase do narcisismo primário.

Ao lado destas concepções, Freud também afirma que a técnica analítica se mostra insuficiente para o tratamento das neuroses narcísicas, pois os indivíduos são incapazes de transferência, a base para todo tratamento analítico:

as neuroses narcísicas dificilmente podem ser abordadas mediante a técnica que nos foi de utilidade nas neuroses de transferência. Em breve os senhores saberão por quê. Com elas, o que acontece é que, após avançarmos uma curta distância, deparamos com um muro que nos força a parar. Nas neuroses de transferência, como sabem, também nos defrontamos com barreiras da resistência, mas conseguimos demoli-las, parte por parte. Nas neuroses narcísicas, a resistência é intransponível; quando muito, somos capazes de lançar um olhar perscrutador por cima do topo do muro e divisar o que se está passando no outro lado. Nossos métodos técnicos, por conseguinte, devem ser substituídos por outros; e nem sequer sabemos se seremos bem sucedidos na busca de um substituto (Freud, 1917/1969: 493).

O tratamento analítico opera por meio da atualização na análise de antigos conflitos e de formas de superação destes conflitos. Este processo, que é relativamente simples nas psiconeuroses, não funciona na paranóia e na melancolia de demência precoce, ambas neuroses narcísicas (Freud, 1917/1969: 511). Para Freud (1917/1969: 519), isto ocorre uma vez que para o paciente ser capaz de transferir afetos e conflitos para a figura do analista deveria haver de sua parte uma capacidade para fazer catexias libidinais de objetos, fato praticamente inviabilizado em indivíduos muito narcísicos. Nestes pacientes, as catexias objetais tiveram que ser abandonadas e a libido objetal se transformou em libi- 
do do ego e, por isto, não manifestam transferência e acabam por ser inacessíveis aos esforços psicanalíticos (Freud, 1917/1969: 521). Freud ainda questiona se somente as vicissitudes da libido, em oposição à pulsão de autopreservação, induzem a patologias. Acreditava que ainda não tinha resposta para esta questão, acrescentando que não deveríamos nos surpreender se nas neuroses graves as pulsões de autopreservação "tiverem perdido sua orientação" (Freud, 1917/ 1969: 501)1. Com isso, Freud reafirmava sua hipótese de que as neuroses atuais têm relação com o represamento da libido, hipótese exposta em no texto "Narcisismo: uma introdução" (1914/1969: 101).

As neuroses narcísicas, assim como as neuroses atuais, que Freud considerava intratáveis por meio do método psicanalítico, pela ausência da transferência, nos fazem pensar em uma hipótese etiológica: nas neuroses narcísicas, a partir da concepção freudiana, a libido regride para fixações muito primárias, da época do narcisismo primário, o que impediria a transferência (embora a transferência maciça na psicose já não seja hoje novidade); nas neuroses atuais e quadros borderline, o que ocorreria, possivelmente, é a fixação no narcisismo primário e a libido, ou pelo menos boa parte dela, nunca se tornaria objetal. Assim, haveria um represamento da libido, mas esse represamento não seria no ego, pois, como propõe Freud, a libido do ego é derivada da libido objetal. A idéia é que nas patologias borderline a libido ficaria represada fora do psiquismo, sendo assim traumática, o que também justificaria a grande dificuldade de transferência observada nestes quadros psicopatológicos.

Com isso, propomos apenas uma primeira formulação, porém acreditamos que essa hipótese se relaciona consistentemente com a idéia de que os quadros borderline se formam onde há uma falha no processo de representação dos objetos da pulsão, pois na medida em que a libido não se liga a um objeto externo ela não encontra um meio de representação; e, também, com a idéia de que, nesses quadros, as fronteiras entre as instâncias são porosas, pois essas fronteiras se formam justamente a partir do vai-e-vem da libido e dos objetos.

Desse modo, podemos concluir que os quadros borderline, freqüentemente associados às denominadas patologias contemporâneas, não são propriamente novos. Contudo, atualmente, contamos com muito mais recursos metapsicológicos para pensá-los. Afinal, lógica e cronologicamente, é só a partir do monumental trabalho freudiano sobre o psiquismo e seu funcionamento que foi possível pensar aquilo que está, senão para além do psiquismo, ao menos em suas bordas; fato que talvez acabe por justificar modos de intervenção que estejam também para além da técnica analítica clássica. 


\section{REFERÊNCIAS BIBLIOGRÁFICAS}

Chabert, C. (1999). Névroses e états limites. Paris: Dunod.

Ferraz, F. (1996). Das neuroses atuais à psicossomática. Percurso, 16 (1), 35-42.

Figueiredo, L. C. (2003). Elementos para uma clínica contemporânea. Escuta: São Paulo.

Freud, S. (1905). Meus pontos de vista sobre o papel da sexualidade na etiologia das neuroses. Obras psicológicas completas de Sigmund Freud, vol. VII. Imago: Rio de Janeiro, 1969.

(1912). Contribuições a um debate sobre a masturbação. Obras psicológicas completas de Sigmund Freud, vol. XII. Imago: Rio de Janeiro, 1969.

. (1914). Narcisismo: uma introdução. Obras psicológicas completas de Sigmund Freud, vol. XIV. Imago: Rio de Janeiro, 1969.

. (1917). Conferências introdutórias à psicanálise. Obras psicológicas completas de Sigmund Freud, vol. XV. Imago: Rio de Janeiro, 1969.

. (1923). Dois verbetes de enciclopédia. Obras psicológicas completas de Sigmund Freud, vol. XVIII. Imago: Rio de Janeiro, 1969.

- (1925). Um estudo autobiográfico. Obras psicológicas completas de Sigmund Freud, vol. XX. Imago: Rio de Janeiro, 1969.

- (1932). Novas conferências introdutórias. Obras psicológicas completas de Sigmund Freud, vol. XXII. Imago: Rio de Janeiro, 1969.

Gurfinkel, D. (1995). A pulsão e o seu objeto, a-droga. Vozes: São Paulo.

Hegenberg, M. (2000). Borderline. Casa do Psicólogo: São Paulo.

Horn, A., e Almeida, M. C. du Pin. (2003). Sobre as bases freudianas da psicossomática psicanalítica: um estudo sobre as neuroses atuais. Revista Brasileira de Psicanálise, 37 (1), 69-84.

Laplanche, J e Pontalis, J. B., (1967). Vocabulário de psicanálise. São Paulo: Martins Fontes, 1991.

Mayer, H. (2004). A técnica ante os desafios clínicos da atualidade. Em Cardoso, M. R. (Org.). Limites (pp. 81-88). Escuta: São Paulo.

Rocha, Z. (2000). Os destinos da angústia na psicanálise freudiana. São Paulo: Escuta.

Safra, G. (2000). Prefácio. Em Hegenberg, M. Borderline (pp. 11-12). Casa do Psicólogo: São Paulo.

Scazufca, A. M. e Berlink, M. T. (2004). Sobre o tratamento psicoterapêutico da anorexia e da bulimia. Em Cardoso, M. R. (Org.). Limites (pp. 89-106). Escuta: São Paulo.

Strachey, J. (1969). Nota do editor. Obras psicológicas completas de Sigmund Freud. Imago: Rio de Janeiro.

Uchitel, M. (1997). Além dos limites da interpretação. São Paulo: Casa do Psicólogo. 
(2002). Novos tempos, novos sintomas: um lugar para a transferência. Percurso, 29 (2), 21-26.

Viluttis, I. M. de. (2002). A construção do dispositivo analítico. Percurso, 29 (2), 27-32.

Zusman, W. (1994). A opção sígnica e o processo simbólico. Revista Brasileira de Psicanálise, 28 (1), 153-64.

\section{NoTAS}

1 Como a fome e a comida no caso da obesidade mórbida. Para isso ver também as considerações de Décio Gurfinkel (1995), Pulsão e seu objeto, a-droga, sobre o objeto-droga.

Recebido em 23 de janeiro de 2006 Aceito para publicação em 30 de maio de 2006 